\title{
Paternal Skin-to-Skin Care and its Effect on Cortisol Levels of the
}

\section{Infants}

\author{
Kayvan Mirnia, ${ }^{1}$ Mohammad Arshadi Bostanabad, ${ }^{2}$ Maliheh Asadollahi, ${ }^{3}$ and Mir Hamid Razzaghi ${ }^{3,}$ \\ ${ }^{1}$ Department of Pediatrics, Faculty of Medicine, Tabriz University of Medical Sciences, Tabriz, Iran \\ ${ }^{2}$ Department of Pediatrics Nursing, Faculty of Nursing and Midwifery, Tabriz University of Medical Sciences, Tabriz, Iran \\ ${ }^{3}$ Faculty of Nursing and Midwifery, Tabriz University of Medical Sciences, Tabriz, Iran \\ "Corresponding author: Mir Hamid Razzaghi, Faculty of Nursing and Midwifery, Tabriz University of Medical Sciences, Tabriz, Iran. Tel: +98-4136676528, Fax: +98-4134796969, \\ E-mail: m.hamid.razzaghi@gmail.com
}

Received 2016 August 06; Revised 2016 September 07; Accepted 2016 September 24.

\begin{abstract}
Background: Neonatal period is one of the most important critical phases of human life. Intensive care unit has a stressful environment for the infant in which the patient will be under the pressure of factors such as noise, nursing intervention and harsh light; the most important factor in this regard being separation from parents.

Objectives: This study aimed to investigate the effect of skin-to-skin care by fathers on salivary cortisol of his infant.

Methods: This study was a randomized clinical trial on 45 premature infants paired by their fathers at the neonatal intensive care unit (NICU) of Tabriz Alzahra teaching hospital conducted during November 2015. The control group received standard care and the intervention group had 45 minutes of skin to skin care. Saliva samples were collected from infants before, during, and after this intervention to measure the cortisol level. The SPSS 13 statistical software was used to analyze the data with the significance level of $\mathrm{P}<0.05$.

Results: Salivary cortisol in babies in the control group had a mean value of 66.36 ( $\mathrm{SD}=71.22$ ) and intervention group a mean value of $59.56(\mathrm{SD}=59.20)(\mathrm{P}=0.56)$.

Conclusions: Both groups showed decreasing cortisol levels during the study, the reduction in the skin-to-skin care group was more than the control group, but with no significant difference. Thus, making it possible for fathers to take care of their infants in an effective, helpful and secure way.
\end{abstract}

Keywords: Paternal Skin Care, Stress, Cortisol, Premature Neonate

\section{Background}

Neonatal period is one of the most critical phases of human life, and any problem in this period has a deep impact on other stages of adult development (1). Premature birth is a worldwide problem; almost 15 million infants, i.e one out of ten infants, are born prematurely, which need intensive nursing care $(2,3)$. In the recent years, it has been emphasized that an environment similar to the uterus should be provided, which has an important role in the development and survival of humans, and can reduce infant mortality $(4,5)$.

On the basis of cosmic evolutionary care considering Als synactive theory, the position of the neonate is similar to the sun, and the family is at closest distance from the infant, so that they can take care of it and play their parental role efficiently (6). Family members have the closest relation with the infant for whom spiritual, physical, and social health of the infant is important $(7,8)$. The infant's skin is a common interface to interact, feel and communicate with the surrounding environment; this originates from the embryonic layer of ectoderm; the brain is also from this section. The outer layers of the skin should be considered as layers of the brain when facing external objects. Synactive theory of Als emphasizes the neurodevelopmental role of skin that helps interaction between the infant and environment as well as care-givers. One of the most important developmental care strategies suitable for the parents is skin-to-skin or Kangaroo mother care (9). This type of care increases the interaction and dependency between parents and the infant with a positive effect on family environment. In addition, touching as well as visual communication of parents with the infant can lead to development of a relationship between parents and the infant and help them understand the infant's behavioral characteristics (10). As for the infant, this care not only keeps the infant warm, but also helps fluctuations in temperature and heart rate, and better respiratory rates $(11,12)$; and with regard to the evolutionary response, the infant has a longer quiet sleep after skin-to-skin care. Meanwhile, the infants show the flexion position more than extension (13), and also painful procedures can be applied easily with the least restrictions during skin-to-skin care $(14,15)$. Studies have 
shown that skin-to-skin care can be done by fathers as efficiently as by mothers (16). Therefore, the word 'Kangaroo mother care' (KMC) is today replaced by 'Kangaroo care' (KC) (17). Studies have also shown that embracing the infant by the father can prevent fluctuations in body temperature, saturation of arterial blood gases and blood glucose drop $(18,19)$. The father can keep the baby quiet by reducing crying and can also prepare for a constructive role in feeding the infant (20). However, it should be noted that the quality of taking care of the infant by the father is not exactly the same as care by the mother, and they are different in emotions (21).

On the other hand, intensive care unit is a stressful environment for the infant and it will be under the pressure of factors such as noise, nursing intervention and harsh light. The most important factor is separation from parents, which is not the same as the life the fetus had in the uterus $(22,23)$. Stress negatively affects the evolutionary behavior of neonates and can create intermediate chemicals and hormones in the body, which will disturb the development of the infant. In addition to immediate negative effects, it can last for the rest of their life $(5,24)$. One of the methods of investigating the degree of stress is measuring the body's cortisol levels; however, it should be noted that stress is not the only reason for secretion of cortisol into the blood stream, and other factors such as nutrition, sleep and sensory simulation can also affect its level (25-27). Nevertheless, since the secretion of cortisol is high during the reaction of the body to stress, and is also responsible for several stress-related changes in the body, it is known as the "stress hormone" (28), introduced in various studies as an indicator to determine the level of stress (29-31). It seems that since skin-to-skin care can soothe the infant, it may decrease stress as well (32).

\section{Objectives}

Previous studies have emphasized the role of the mother, and it seems that the care given by the father is different from the care given by the mother. Although most previous investigations of the stress of neonates have been based on observations, different results have been reported about the effects of care taking. Thus, in this study, we aimed to achieve more objective results regarding the effect of skin-to-skin care on the infant.

\section{Methods}

This was a randomized clinical trial on 45 premature infants and their fathers at the neonatal intensive care unit (NICU) of Tabriz Alzahra teaching hospital conducted in November 2015. From 98 hospitalized premature neonates, the eligible ones were chosen by using Rand List software through blocks of four and six, and then randomly divided into two groups of intervention and control. For the sake of privacy, the blocks with different sizes were marked with letters A or B on envelopes numbered 1 to 45 so that the first eligible participant corresponded to envelope No.1, and so on. By opening the envelope we determined the group of the infant. Written informed consent forms were obtained from the fathers of both groups.

The inclusion criteria for this study for the infants were premature weight of 1200 to 2500 gr; absence of breathing or heart problems; five-minute Apgar score of more than seven; absence of receiving sedatives; absence of jaundice or infection; no procedures in the past hour; the infant being fed; and no deficiency in the hypothalamicpituitary-adrenal axis. Inclusion criteria for the fathers were: literacy, mental stability, and absence of any impairment affecting the implementation of care. The exclusion criteria were instability of breathing and temperature, and also inefficiency of the amount of samples.

In the case of neonates, unlike adults, there was no circadian rhythm for cortisol (30) and sampling of both groups was performed between 3 and $6 \mathrm{pm}$, during fathers visit time. In the control group, interventions and routine care were performed with attendance of the fathers that only watched their neonates. In order to unify sampling time, collection of saliva samples was carried out in both groups at intervals of onset (sample 1), 45 minutes after onset (sample 2) and one hour after onset (sample 3).

After verbal instructions and providing educational pamphlets for parents in the intervention group, the infants were placed in the fetal position or flexion on the fathers' chest with maximum direct skin-to-skin contact for 45 minutes while wearing only a diaper and a hat. A room near the ward with air temperature of 22 to $26^{\circ} \mathrm{C}$ and a relative humidity of 30 to $60 \%$, facilities such as a bed and a recliner for sitting and leaning, was provided for the father. The fathers cuddled the infants and gave them supportive care in a quiet environment while wearing clean and open front clothes with no odors. Then, the infants were covered by a thin blanket while being on the fathers' chest, which looked like a bag providing a flexed position for the infant with no pressure or twisting. We kept the temperature adjusted.

Saliva samples were collected to measure cortisol levels in the intervention group, at five-minute intervals before, 45 minute after the start, and 15 minute after the intervention of skin-to-skin care of the infants. The first sample taken from the infants was the baseline for determining changes in the cortisol level. Saliva samples were collected 
between two feedings. The mouth of the infants was rinsed with distilled water to clean up the remaining milk before collecting saliva. Whatman filter paper $42^{\circ}$ was used to minimize irritation (33). For this purpose, size $1 \times 4$ sterile filter papers were placed under the infants' tongue slowly from the corner of the lips, and when saturated removed after 15 to 30 seconds. If the saturation and absorption was enough, the procedure was repeated. It was also repeated after 15 minutes, if milk or sputum were stuck on the paper. One centimeter of the saturated end was cut, put in a round-bottom tube $($ size $12 \times 75)$ already filled with 0.5 $\mathrm{mL}$ of buffer solution and labeled with the name of the infant. A gentle shaking of the tube caused the filter paper to soak the buffer solution completely. One centimeter of the filter paper could collect $0.1 \mathrm{~mL}$ of saliva (34). Maintaining cold chain $\left(4^{\circ} \mathrm{C}\right)$, the tube was transferred to the laboratory where the samples were centrifuged for five minutes with $3500 \mathrm{rpm}$ and poured in a microtube kept at $-70^{\circ} \mathrm{C}$ until analysis. The analysis was performed by the enzyme linked immunosorbent assay (ELISA) using a kit of human saliva cortisol (IBL co., Germany) and measured with the sensitivity of $0.01 \mu \mathrm{g} / \mathrm{dL}$. We measured the light absorption of the materials with a photometer at wavelength $450 \mathrm{~nm}$ within 15 minutes after pipetting of the stop solution. Physiologic stability, heart rate, respiratory and arterial oxygen saturation along with armpit temperature in the intervention group were monitored. The SPSS 13 software was used to analyze the data with significance level of $P<0.05$. To investigate the correlation between the quantitative variables of infants and their fathers, we used independent-samples t-test; however, for the qualitative variables, we used chisquared and Fisher's tests. To compare the changes of cortisol in the infants of the same group within three different time intervals, we used repeated measuring test; however, to compare the groups we used independent-samples t-test.

To start this study, all required permissions from stakeholders, including the participants, while respecting their privacy, was obtained. Meanwhile, we notified the participants that they were to quit the study if they changed their mind. As a sign of appreciation, participants received gifts. The research protocol was approved (Code TBZMED.REC.1394.489) by the ethics committee of Tabriz University of Medical Sciences in August 2015 and registered at the Iranian Registry of clinical trials with IRCT2015081513691N5 on 13th of November 2015.

\section{Results}

A total of 45 neonates along with their parents took part in this study, 22 of which were in the control and 23 were in the intervention group. The percentages of cesarean section in the intervention and control groups were $72.7 \%$ and $73.9 \%$, respectively. There were no significant differences in the results of t-test in terms of circumference of the head, height, birth weight, duration of hospitalization, and the amount of feeding between the two groups of infants. In addition, there was no significant difference among fathers in terms of weight and working hours in a day using independent-samples t-test (Table 1).

Changes in cortisol levels of the infants in both groups were evaluated before, during and after the intervention. Although both groups showed decreasing cortisol levels during the study, the reduction in the skin-to-skin care group was more than the control group, with no significant difference between the two groups (Table 2).

Independent-samples t-test for comparing cortisol changes between the two groups before, during, and after the intervention showed no significant statistical difference at any time interval of the study (Table 3).

\section{Discussion}

Cortisol is the body's most well-known glucocorticoid secreted from the adrenal glands (35). Physical and psychological stress can activate the hypothalamic-pituitaryadrenal axis. The hypothalamus is stimulated by various types of stress that activate this system and release cortisol quickly in order to reduce harmful metabolic effects of stress $(35,36)$.

Moreover, direct feedback of cortisol on both hypothalamus and anterior pituitary gland reduces plasma concentrations of cortisol at times when the body is under stress (37). Cortisol in the saliva is a free metabolite (active form) and is correlated with concentrations of free cortisol of plasma (38). This is the first study in Iran for investigating the effects of skin-to-skin care of fathers on the cortisol levels of neonates that confirmed care by fathers is possible, secure and effective.

This study used filter paper for collecting saliva of neonates, which confirmed practicality by previous studies $(33,34)$. This method can be a reliable mechanism since it is accurate, suitable, and safe, and can provide an adequate sample size with the least stimulation. This study aimed to investigate the effects of skin-to-skin care of fathers on saliva cortisol levels of neonates. Neonates were examined at three time intervals. Based on the results of the present study, cortisol in neonates decreased in both groups of skin-to-skin and standard care of the ward, but this decrease was not statistically significant. The cortisol level in neonates during skin-to-skin care decreased more in comparison with similar time intervals in the group with standard care. Moreover, in the third time interval, in 
Table 1. Demographic Characteristics of the Infants and Parents in Different Groups ${ }^{\mathrm{a}}$

\begin{tabular}{|c|c|c|c|c|c|}
\hline \multirow[t]{2}{*}{ Variable } & \multirow[t]{2}{*}{ Standard Care $(n=22)$} & \multirow[t]{2}{*}{ Skin-to-Skin Care $(n=23)$} & \multicolumn{3}{|c|}{ Statistical Test } \\
\hline & & & $\mathbf{t}, \chi^{2}$ & df & P Value \\
\hline \multicolumn{6}{|l|}{ Neonates } \\
\hline Gestational age, $\mathrm{w}$ & $31.35 \pm 2.31$ & $32 \pm 2.73$ & -0.87 & 42.81 & $0.39^{\mathrm{b}}$ \\
\hline Age at the time of study, d & $17.09 \pm 13.6$ & $15.39 \pm 14.78$ & 0.4 & 43.7 & $0.69^{\mathrm{b}}$ \\
\hline Weight at the time of study, $g$ & $1788.26 \pm 407.75$ & $1906.96 \pm 465.57$ & -0.92 & 43.25 & $0.36^{\mathrm{b}}$ \\
\hline 1-min Apgar & $7.17 \pm 1.37$ & $6.74 \pm 1.71$ & 0.95 & 41.99 & $0.35^{\mathrm{b}}$ \\
\hline 5-min Apgar & $8.61 \pm 0.99$ & $8.39 \pm 1.08$ & 0.71 & 43.68 & $0.48^{\mathrm{b}}$ \\
\hline Boy/girl, No & $15 / 7$ & $16 / 7$ & 7.04 & 1 & $0.008^{\mathrm{c}}$ \\
\hline NGT/OG, No & $19 / 3$ & $15 / 8$ & 12.52 & 1 & $0.001^{c}$ \\
\hline \multicolumn{6}{|l|}{ Fathers } \\
\hline Age, $y$ & $32.78 \pm 6.19$ & $33.04 \pm 5.34$ & -0.15 & 43.06 & $0.88^{\mathrm{b}}$ \\
\hline Weight, kg & $81.43 \pm 15.04$ & $80.52 \pm 16.79$ & -0.19 & 43.48 & $0.85^{\mathrm{b}}$ \\
\hline Education (Basic/Intermediate/high), No & $6 / 12 / 4$ & $9 / 7 / 7$ & 9.48 & 3 & $0.02^{\mathrm{c}}$ \\
\hline \multicolumn{6}{|c|}{$\begin{array}{l}\text { Abbreviations: NG, oral intake; NGT, nasal-gastric feeding tube. } \\
\text { a Values are expressed as mean } \pm \text { SD. } \\
\text { b Independent-samples t-test. } \\
\text { c }\end{array}$} \\
\hline
\end{tabular}

Table 2. Change in the Infants' Saliva Cortisol Levels in Both Groups During the Study (ng/dL) ${ }^{\mathrm{a}}$

\begin{tabular}{|c|c|c|c|c|c|c|}
\hline \multirow[t]{2}{*}{ Variable } & \multirow[t]{2}{*}{ Group } & \multirow[t]{2}{*}{ Before } & \multirow[t]{2}{*}{ During } & \multirow[t]{2}{*}{ After } & \multicolumn{2}{|c|}{ Statistical Test } \\
\hline & & & & & Multivariate Tests & $\begin{array}{c}\text { Pairwise } \\
\text { Comparison }\end{array}$ \\
\hline \multirow{6}{*}{$\begin{array}{l}\text { Salivary Cortisol of } \\
\text { the Infants }\end{array}$} & \multirow{3}{*}{$\begin{array}{c}\text { Standard care }(\mathrm{n}= \\
22)\end{array}$} & \multirow{3}{*}{$70.91 \pm 62.33$} & \multirow{3}{*}{$69.09 \pm 69.27$} & \multirow{3}{*}{$66.36 \pm 71.22$} & \multirow{3}{*}{$P=0.96$} & $\mathrm{P} 1-2=0.92$ \\
\hline & & & & & & $P 1-3=0.78$ \\
\hline & & & & & & $\mathrm{P} 2-3=0.84$ \\
\hline & \multirow{3}{*}{$\begin{array}{l}\text { Skin-to- skin care (n } \\
=23 \text { ) }\end{array}$} & \multirow{3}{*}{$83.48 \pm 81.33$} & \multirow{3}{*}{$65.65 \pm 72.91$} & \multirow{3}{*}{$59.56 \pm 59.20$} & \multirow{3}{*}{$P=0.56$} & $\mathrm{P} 1-2=0.48$ \\
\hline & & & & & & $\mathrm{P} 1-3=0.30$ \\
\hline & & & & & & $\mathrm{P} 2-3=0.63$ \\
\hline
\end{tabular}

${ }^{\mathrm{a}}$ Values are expressed as mean $\pm \mathrm{SD}$

Table 3. Comparison of Changes in Cortisol Levels Between the Two Groups at Three Different Times (ng/dL)

\begin{tabular}{|c|c|c|c|c|c|}
\hline \multirow[t]{2}{*}{ Cortisol Time } & \multirow[t]{2}{*}{ Standard Care $(\mathbf{n}=\mathbf{2 2})$} & \multirow[t]{2}{*}{ Skin-to-Skin Care $(\mathbf{n}=23)$} & \multicolumn{3}{|c|}{ Statistical Test* } \\
\hline & & & $\mathbf{t}$ & df & PValue \\
\hline Before & $70.91 \pm 62.33$ & $83.48 \pm 81.33$ & 0.58 & 43 & 0.56 \\
\hline During & $69.09 \pm 69.27$ & $65.65 \pm 72.91$ & 0.16 & 43 & 0.87 \\
\hline After & $66.36 \pm 71.22$ & $59.56 \pm 59.2$ & 0.35 & 43 & 0.73 \\
\hline
\end{tabular}

${ }^{\mathrm{a}}$ Values are expressed as mean $\pm \mathrm{SD}$.

which the infants were separated from the chest of their fathers and received standard care, the infants experienced a similar slope, as did the control group (Figure 1).
These results confirm the results obtained by Morelius et al. (2005), in which mothers performed skin-to-skin care. Mothers participated in care four times, and the cor- 


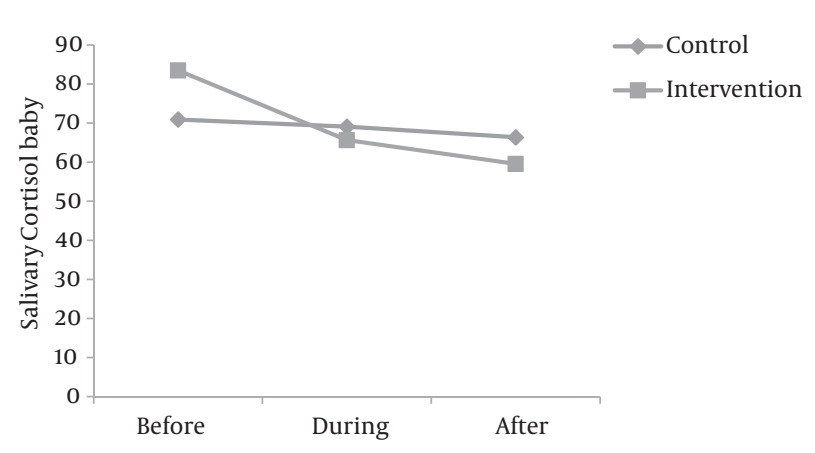

Figure 1. The Mean Salivary Cortisol Levels of Infants at Three Time Points

tisol level was measured at the first and the fourth time (30). The effect of skin-to-skin care of premature neonates was investigated by Takahashi et al. (2010), which showed no considerable difference in saliva cortisol level between the groups being taken care for 60 minutes or less, which confirms our results; however, their investigation on the group receiving care for more than 60 minutes showed a considerable drop in the cortisol level (31). The plasma cortisol level was measured in a study by Mooncey (1997), in which the effect of skin-to-skin care on premature infants was investigated. After 20 minutes of care, plasma cortisol declined, which is in conflict with our results and also the control group in their study showed a significant drop (39); Mitchell et al. (2013) showed that salivary cortisol level of infants receiving continuous kangaroo mother care decreased on the fifth and tenth day of life (40). To evaluate the effects of massage on premature infants, Acolet et al. (1993) found a decrease in plasma cortisol concentration, but this was not significant (41). Cong et al. (2011) selected two groups of preterm neonates and investigated the effects of kangaroo care and heel needling. The first group received 80 minute and the second group received 30 minute of KMC. The first group did not show any significant drop in cortisol, but the second group showed a significant decrease in serum and salivary cortisol level (42). Jang (2008) investigated the effects of kangaroo care on preterm neonates' cortisol level. The cortisol level decrease in the group receiving KMC was more than the control group, and this difference was statistically significant (43).

One of the limitations of this study was the insufficiency of the samples and thus it is possible that different results may be achieved by including more participants. Since the role and effects of KC of fathers has been studied less, it may be better to investigate their care for premature neonates and compare the effects of physiological parameters between groups.

\subsection{Conclusions}

This study did not show a significant decrease in salivary cortisol level of the infants after skin-to-skin care. Nevertheless, the established effects of KFC cannot be ignored. Thus, making it possible for fathers to take care of their infants may be effective, helpful and secure.

\section{Acknowledgments}

This study was conducted at Tabriz Alzahra hospital. The researchers involved in this study appreciate and express their gratitude to all committed, hard-working staff, and the fathers who participated in this study.

\section{Footnote}

Funding/Support: This study was funded by the research vice-chancellor of Tabriz University of Medical Sciences.

\section{References}

1. Gluckman PD, Hanson MA, Cooper C, Thornburg KL. Effect of in utero and early-life conditions on adult health and disease. $N$ Engl J Med. 2008;359(1):61-73. doi: 10.1056/NEJMra0708473. [PubMed:18596274].

2. WHO . Preterm birth: World Health Organization 2015. Available from: http://www.who.int/mediacentre/factsheets/fs363/en/.

3. Kenner C, Lott JW. Comprehensive neonatal nursing care. Springer Publishing Company; 2013.

4. White RD. The newborn intensive care unit environment of care: how we got here, where we're headed, and why. Seminars Perinatol. 2011;35(1):2-7.

5. Davis EP, Sandman CA. The timing of prenatal exposure to maternal cortisol and psychosocial stress is associated with human infant cognitive development. Child Dev. 2010;81(1):131-48. doi: 10.1111/j.14678624.2009.01385.x. [PubMed: 20331658].

6. Verklan MT, Walden M. Core curriculum for neonatal intensive care nursing. Elsevier Health Sciences; 2014.

7. Sharma A, Cockerill H. Mary Sheridan's from birth to five years: Children's Developmental Progress. Routledge; 2014.

8. Gooding JS, Cooper LG, Blaine AI, Franck LS, Howse JL, Berns SD. Family support and family-centered care in the neonatal intensive care unit: origins, advances, impact. Seminars Perinatol. 2011;1.

9. Nyqvist KH, Anderson GC, Bergman N, Cattaneo A, Charpak N, Davanzo R, et al. Towards universal Kangaroo Mother Care: recommendations and report from the First European conference and Seventh International Workshop on Kangaroo Mother Care. Acta Paediatr. 2010;99(6):820-6. doi: 10.1111/j.1651-2227.2010.01787.x. [PubMed: 20219044].

10. Charpak N, Ruiz JG, Zupan J, Cattaneo A, Figueroa Z, Tessier R, et al. Kangaroo Mother Care: 25 years after. Acta Paediatr. 2005;94(5):51422. doi: 10.1080/08035250510027381. [PubMed: 16188735].

11. Ludington-Hoe SM, Hosseini R, Torowicz DL. Skin-to-skin contact (Kangaroo Care) analgesia for preterm infant heel stick. AACN Clin Issues. 2005;16(3):373-87. [PubMed: 16082239].

12. Bera A, Ghosh J, Singh AK, Hazra A, Som T, Munian D. Effect of kangaroo mother care on vital physiological parameters of the low birth weight newborn. Indian J Community Med. 2014;39(4):245-9. doi: 10.4103/0970-0218.143030. [PubMed: 25364150]. 
13. Ferber SG, Makhoul IR. The effect of skin-to-skin contact (kangaroo care) shortly after birth on the neurobehavioral responses of the term newborn: a randomized, controlled trial. Pediatrics. 2004;113(4):85865. [PubMed: 15060238].

14. Akcan E, Yigit R, Atici A. The effect of kangaroo care on pain in premature infants during invasive procedures. TurkJPediatr. 2009;51(1):14-8. [PubMed: 19378885].

15. Benoit B, Campbell-Yeo M, Johnston C, Latimer M, Caddell K, Orr T. Staff Nurse Utilization of Kangaroo Care as an Intervention for Procedural Pain in Preterm Infants. Adv Neonatal Care. 2016;16(3):229-38. doi: 10.1097/ANC.0000000000000262. [PubMed: 27148835].

16. Velandia M, Uvnas-Moberg K, Nissen E. Sex differences in newborn interaction with mother or father during skin-to-skin contact after Caesarean section. Acta Paediatr. 2012;101(4):360-7. doi: 10.1111/j.16512227.2011.02523.x. [PubMed: 22077187].

17. Jefferies AL, Canadian Paediatric Society F, Newborn C. Kangaroo care for the preterm infant and family. Paediatr Child Health. 2012;17(3):1416. [PubMed: 23449885].

18. Bauer J, Sontheimer D, Fischer C, Linderkamp O. Metabolic rate and energy balance in very low birth weight infants during kangaroo holding by their mothers and fathers. J Pediatr. 1996;129(4):608-11. [PubMed: 8859271].

19. Christensson K. Fathers can effectively achieve heat conservation in healthy newborn infants. Acta Paediatr. 1996;85(11):1354-60. [PubMed: 8955466].

20. Erlandsson K, Dsilna A, Fagerberg I, Christensson K. Skin-to-skin care with the father after cesarean birth and its effect on newborn crying and prefeeding behavior. Birth. 2007;34(2):105-14. doi: 10.1111/j.1523536X.2007.00162.x. [PubMed: 17542814].

21. Lamb ME. The role of the father in child development. John Wiley \& Sons; 2004

22. Peng $\mathrm{NH}$, Bachman J, Jenkins R, Chen $\mathrm{CH}$, Chang $\mathrm{YC}$, Chang $\mathrm{YS}$ et al. Relationships between environmental stressors and stress biobehavioral responses of preterm infants in NICU. Adv Neonatal Care. 2013;13 Suppl 5:S2-10. doi: 10.1097/ANC.0000000000000023. [PubMed: 24042180].

23. Slotten HA, Kalinichev M, Hagan JJ, Marsden CA, Fone KC. Longlasting changes in behavioural and neuroendocrine indices in the rat following neonatal maternal separation: gender-dependent effects. Brain Res. 2006;1097(1):123-32. doi: 10.1016/j.brainres.2006.04.066. [PubMed: 16730678].

24. Shonkoff JP, Garner AS, Committee on Psychosocial Aspects of C, Family H, Committee on Early Childhood A, Dependent C, et al. The lifelong effects of early childhood adversity and toxic stress. Pediatrics. 2012;129(1):e232-46. doi: 10.1542/peds.2011-2663. [PubMed: 22201156].

25. Ghaly M, Teplitz D. The biologic effects of grounding the human body during sleep as measured by cortisol levels and subjective reporting of sleep, pain, and stress. J Altern Complement Med. 2004;10(5):767-76. doi:10.1089/acm.2004.10.767. [PubMed:15650465].

26. Witbracht M, Keim NL, Forester S, Widaman A, Laugero K. Female breakfast skippers display a disrupted cortisol rhythm and elevated blood pressure. Physiol Behav. 2015;140:215-21. doi: 10.1016/j.physbeh.2014.12.044. [PubMed: 25545767].

27. Sanger J, Bechtold L, Schoofs D, Blaszkewicz M, Wascher E. The influence of acute stress on attention mechanisms and its electrophysiological correlates. Front Behav Neurosci. 2014;8:353. doi: 10.3389/fnbeh.2014.00353. [PubMed: 25346669].

28. Blaney PH, Millon T. Oxford textbook of psychopathology. Oxford University Press; 2008
29. White-Traut RC, Schwertz D, McFarlin B, Kogan J. Salivary cortisol and behavioral state responses of healthy newborn infants to tactile-only and multisensory interventions. J Obstet Gynecol Neonatal Nurs. 2009;38(1):22-34. doi:10.1111/j.1552-6909.2008.00307.x. [PubMed: 19208045].

30. Morelius E, Theodorsson E, Nelson N. Salivary cortisol and mood and pain profiles during skin-to-skin care for an unselected group of mothers and infants in neonatal intensive care. Pediatrics. 2005;116(5):1105-13. doi: 10.1542/peds.2004-2440. [PubMed: 16263996].

31. Takahashi Y, Tamakoshi K, Matsushima M, Kawabe T. Comparison of salivary cortisol, heart rate, and oxygen saturation between early skin-to-skin contact with different initiation and duration times in healthy, full-term infants. Early Hum Dev. 2011;87(3):151-7. doi 10.1016/j.earlhumdev.2010.11.012. [PubMed: 21220191].

32. Tuomi K. The effects of combining kangaroo care and parental singing on premature infants' and parents' wellbeing and development of parent-infant relationship 2014. Available from: https://jyx. jyu.fi/dspace/handle/123456789/44215.

33. Neu M, Goldstein M, Gao D, Laudenslager ML. Salivary cortisol in preterm infants: validation of a simple method for collecting saliva for cortisol determination. Early Human Dev. 2007;83(1):47-54.

34. Granger DA, Kivlighan KT, Fortunato C, Harmon AG, Hibel LC Schwartz EB, et al. Integration of salivary biomarkers into developmental and behaviorally-oriented research: problems and solutions for collecting specimens. Physiol Behav. 2007;92(4):583-90. doi 10.1016/j.physbeh.2007.05.004. [PubMed:17572453].

35. Hall JE. Guyton and Hall textbook of medical physiology. Elsevier Health Sciences; 2015.

36. Putman P, Hermans EJ, van Honk J. Cortisol administration acutely reduces threat-selective spatial attention in healthy young men. Physiol Behav. 2010;99(3):294-300. doi: 10.1016/j.physbeh.2009.11.006 [PubMed: 19931549].

37. Tasker JG, Herman JP. Mechanisms of rapid glucocorticoid feedback inhibition of the hypothalamic-pituitary-adrenal axis. Stress. 2011;14(4):398-406. doi: 10.3109/10253890.2011.586446. [PubMed: 21663538].

38. Duplessis C, Rascona D, Cullum M, Yeung E. Salivary and free serum cortisol evaluation. Mil Med. 2010;175(5):340-6. [PubMed: 20486506].

39. Mooncey S, Giannakoulopoulos X, Glover V, Acolet D, Modi N. The effect of mother-infant skin-to-skin contact on plasma cortisol and $\beta$-endorphin concentrations in preterm newborns. Infant Behav Dev. 1997;20(4):553-7.

40. Mitchell AJ, Yates CC, Williams DK, Chang JY, Hall RW. Does daily kangaroo care provide sustained pain and stress relief in preterm infants?. J Neonatal Perinatal Med. 2013;6(1):45-52. doi: 10.3233/NPM1364212. [PubMed: 24246458].

41. Acolet D, Modi N, Giannakoulopoulos X, Bond C, Weg W, Clow A, et al. Changes in plasma cortisol and catecholamine concentrations in response to massage in preterm infants. Arch Dis Child. 1993;68(1 Spec No):29-31. [PubMed: 8439193].

42. Cong X, Ludington-Hoe SM, Walsh S. Randomized crossover trial of kangaroo care to reduce biobehavioral pain responses in preterm infants: a pilot study. Biol Res Nurs. 2011;13(2):204-16. doi: 10.1177/1099800410385839. [PubMed: 21196428].

43. Jang M. The effect of kangaroo care on weight and stress hormone (cortisol) in premature infants. $J$ Korean Acad Child Health Nurs. 2008;14(2):138-45. 